\title{
Metabolic Fate of Extracted Glucose in Normal Human Myocardium
}

\author{
Judith A. Wisneski, Edward W. Gertz, Richard A. Neese, Larry D. Gruenke, D. Lynn Morris, and J. Cymerman Craig \\ Departments of Medicine, Radiology, and Pharmaceutical Chemistry, and Cardiovascular Research Institute, University of California at \\ San Francisco, and Veterans Administration Medical Center, San Francisco, California 94121
}

\begin{abstract}
Glucose is an important substrate for myocardial metabolism. This study was designed to determine the effect of circulating metabolic substrates on myocardial glucose extraction and to determine the metabolic fate of glucose in normal human myocardium. Coronary sinus and arterial catheters were placed in 23 healthy male volunteers. $\left[6-{ }^{14} \mathrm{C}\right]$ Glucose was infused as a tracer in 10 subjects. $\left[6-{ }^{14} \mathrm{C}\right]$ Glucose and $\left[\mathrm{U}-{ }^{13} \mathrm{C}\right]$ lactate were simultaneously infused in the other 13 subjects. Simultaneous blood samples were obtained for chemical analyses of glucose, lactate, and free fatty acids and for the isotopic analyses of glucose and lactate. Glucose oxidation was assessed by measuring myocardial ${ }^{14} \mathrm{CO}_{2}$ production. The amount of glucose extracted and oxidized by the myocardium was inversely correlated with the arterial level of free fatty acids $(r=-0.71 ; P<0.0001) .20 \%$ (range, 0 $63 \%$ ) of the glucose extraction underwent immediate oxidation. Chemical lactate analysis showed a net extraction of $26.0 \pm 16.4 \%$. However, isotopic analysis demonstrated that lactate was being released by the myocardium. In the 13 subjects receiving the dual-carbon-labeled isotopes, the lactate released was $0.09 \pm 0.04$ $\mu \mathrm{mol} / \mathrm{ml}$ and $49.5 \pm 29.5 \%$ of this lactate was from exogenous glucose. This study demonstrates that the circulating level of free fatty acids plays a major role in determining the amount of glucose extracted and oxidized by the normal human myocardium. Only $20.1 \pm 19.4 \%$ of the glucose extracted underwent $0 x-$ idation, and $13.0 \pm 9.0 \%$ of the glucose extracted was metabolized to lactate and released by the myocardium. Thus, $60-70 \%$ of the glucose extracted by the normal myocardium is probably stored as glycogen in the fasting, resting state.
\end{abstract}

\section{Introduction}

The myocardium is capable of using various substrates as its energy source. Free fatty acids and glucose are two of the major substrates for myocardial oxidative metabolism (1-4). During ischemia and hypoxia, glycolysis is accelerated and glucose utilization is enhanced (4-8). Glucose-insulin-potassium infusions have been advocated for patients with acute myocardial infarctions and chronic ischemic heart disease; however, the efficacy of this treatment for limiting myocardial infarct size and left ventricular dysfunction still remains to be determined $(3,9-17)$.

More recently, positron-emission tomography has been used to investigate myocardial glucose extraction in normal and various disease states (18-21). The glucose analogue ${ }^{18} \mathrm{~F}$-2-fluoro2-deoxyglucose used in this technique is extracted by the myocardium but is not actively metabolized (18). Enhanced myocardial uptake of ${ }^{18} \mathrm{~F}$-2-fluoro-2-deoxyglucose is often equated with reversibly ischemic myocardium $(19,20)$. To better utilize

Address correspondence to Dr. Wisneski, Veterans Administration Medical Center, 4150 Clement St., San Francisco, CA 94121.

The Journal of Clinical Investigation, Inc.

Volume 76, November 1985, 1819-1827 this technology, we need to know whether other factors, in addition to ischemia, are important determinants of myocardial glucose uptake and metabolism. Many of the investigations of myocardial substrate metabolism have been performed in isolated heart preparations or anesthetized animals. Much valuable information concerning various metabolic pathways has been obtained from these experiments. However, in many studies, the perfusion media contained only a single substrate, and in others, the circulating substrate levels were often not in the physiologic range for humans.

The purpose of this study was to determine the effect, if any, of circulating metabolic substrates on myocardial glucose extraction and to determine the metabolic fate of this important substrate in normal human myocardium. Previous investigations $(12,22)$ in humans have used the arterial-coronary sinus chemical difference in determining the myocardial uptake of a substrate, and the uptake of the substrate has often been equated with substrate oxidation. In this study, D-[6- $\left.{ }^{14} \mathrm{C}\right]$ glucose was infused as a tracer and the myocardial production of ${ }^{14} \mathrm{CO}_{2}$ was measured to quantitate the myocardial oxidation of circulating exogenous glucose. To assess the conversion of glucose to lactate by the myocardium, a stable isotope (L- $\left[\mathrm{U}_{-}{ }^{13} \mathrm{C}\right]$ lactate) was infused simultaneously with the glucose tracer in a subset of the subjects.

\section{Methods}

Subject selection. Young healthy male volunteers were sought. The volunteers underwent a complete history, physical examination, and laboratory tests. The laboratory tests included an electrocardiogram, complete blood count, liver and thyroid function tests, fasting, and 2-hour postprandial glucose, blood urea nitrogen, urine, and creatinine analysis. Each subject had to complete at least stage $\mathrm{V}$ of the standard Bruce protocol (23) and reach $95 \%$ of his maximal predicted heart rate (24) on a treadmill exercise test. In addition, the subject could not be $<5 \%$ or $>15 \%$ of his predicted weight. Subjects with a history of chronic drug use, smoking, or a family history of diabetes were excluded. If there was no evidence of cardiac or any major systemic illness and all the laboratory tests were within normal limits, the volunteer was accepted as a subject. The examination and exercise test were performed at least $1 \mathrm{wk}$ before the metabolic study.

The protocol was approved by the Committees on Human Research of the University of California and the Veterans Administration Medical Center at San Francisco, CA. The use of radioisotopes was approved by the Radiation Safety Committee of the Veterans Administration Medical Center. Each subject was informed of the nature, purpose, and possible risks involved in the study before written consent was obtained.

Protocol. All subjects fasted for $10-15 \mathrm{~h}$ before the procedure. No premedication was given. A local anesthetic ( $2 \%$ lidocaine) was used to perform a venous cutdown; a 7F Wilson Webster thermodilution-flow coronary sinus catheter was inserted into an anteromedial antecubital vein and positioned under fluoroscopy in the mid-to-anterior region of the coronary sinus (25). The position was checked by pressure and oximetry measurements; no contrast agent was injected (26). The stability of the catheter position through the entire protocol was verified by comparison of videodisc images recorded at the beginning and at the end of the procedure. For arterial blood samples, a short polyethylene catheter 
was inserted into the brachial artery by the Seldinger technique. The patency of the catheters was maintained by intermittent flushing with $0.9 \%$ normal saline (no heparin was used for this purpose).

D- $\left[6-{ }^{14} \mathrm{C}\right]$ Glucose was obtained from New England Nuclear, Boston, MA (sp act, $56.1 \mathrm{mCi} / \mu \mathrm{mol})$. It was sterilized by ultrafiltration $(0.22-$ $\mu \mathrm{m}$ bacteriologic filter [Millipore Corp., Bedford, MA]) and diluted in $0.9 \% \mathrm{NaCl}$. After a priming bolus of $16 \mu \mathrm{Ci}, \mathrm{D}-\left[6-{ }^{14} \mathrm{C}\right]$ glucose was infused intravenously at a constant rate of $10 \mu \mathrm{Ci} / \mathrm{h}$.

L- $\left[\mathrm{U}-{ }^{13} \mathrm{C}\right]$ Lactate ( $99 \%$ isotopic purity) was obtained from Los Alamos Scientific Laboratory, Los Alamos, NM as $\mathrm{L}-\left[\mathrm{U}-{ }^{13} \mathrm{C}\right]$ zinc lactate. This was converted to $\mathrm{L}-\left[\mathrm{U}-{ }^{13} \mathrm{C}\right]$ lactic acid by dissolving the zinc lactate in distilled water and passing the solution through a cation exchange column (27). The resulting solution of $\left[\mathrm{U}-{ }^{13} \mathrm{C}\right]$ lactic acid was neutralized with $1.0 \mathrm{M} \mathrm{NaOH}$ and sterilized as above. To ensure that the preparation was pyrogen-free, the Limulus lysate test was performed (28). To achieve a steady arterial level of [U- $\left.{ }^{13} \mathrm{C}\right]$ lactate of $1.5-2.0 \%$ of the circulating chemical lactate, a priming dose of $55 \mathrm{mg}$ of $\left[\mathrm{U}_{-}{ }^{13} \mathrm{C}\right]$ lactate infused intravenously over 2 min was required. This was followed immediately by an intravenous infusion of the stable isotope at a constant rate of 65 $\mathrm{mg} / \mathrm{h}$. D- $\left[6-{ }^{14} \mathrm{C}\right]$ glucose was infused simultaneously (as described above) in the subset of subjects receiving the dual-carbon-labeled isotopes.

Fig. 1 shows the equilibration of the arterial and coronary sinus specific activity of glucose in an individual subject. A priming dose of $16 \mu \mathrm{Ci}$ of $\left[6-{ }^{14} \mathrm{C}\right]$ glucose was given at time 0 , and a constant intravenous infusion at a rate of $10 \mu \mathrm{Ci} / \mathrm{h}$ was started at that time. Using this infusion technique, the arterial and coronary sinus specific activities of glucose reached a plateau after $30 \mathrm{~min}$. The myocardial production (coronary sinus-arterial) of ${ }^{14} \mathrm{CO}_{2}$ is also shown in Fig. 1 for the same individual subject. The ${ }^{14} \mathrm{CO}_{2}$ equilibrates with the myocardial $\mathrm{CO}_{2}$ pool within $25-30 \mathrm{~min}$. We have previously shown $(27,29)$ that $20 \mathrm{~min}$ is required to achieve equilibration for the specific activity and myocardial $\mathrm{CO}_{2}$ pool when lactate is labeled with a tracer. Thus, to ensure equilibration of the isotopes, all samples were obtained at least $30 \mathrm{~min}$ after the initiation of the [6${ }^{14} \mathrm{C}$ ]glucose or dual-isotope infusion. Arterial and coronary sinus blood samples were drawn simultaneously. At least two sets of blood samples were obtained 8-10 min apart in all subjects. All samples were obtained with the subjects in the resting state. In order to elevate the circulating level of free fatty acids, heparin $(10,000 \mathrm{U})$ was administered to five subjects.

The samples were analyzed for chemical concentration of glucose, lactate, and free fatty acids and the specific activity of glucose and lactate. In the subset of subjects receiving $\mathrm{L}-\left[\mathrm{U}-{ }^{13} \mathrm{C}\right]$ lactate, the samples were also analyzed for $\left[{ }^{13} \mathrm{C}\right]$ lactate.

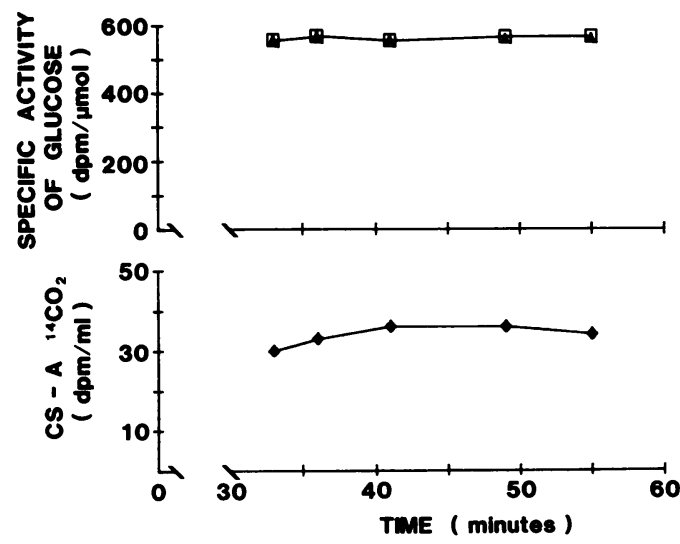

Figure 1. The arterial and coronary sinus specific activities of glucose are shown over time in a subject (top graph). At time 0 , the priming dose of $16 \mu \mathrm{Ci} \mathrm{D}-\left[6-{ }^{14} \mathrm{C}\right]$ glucose was given and an intravenous constant infusion was started at a rate of $10 \mu \mathrm{Ci} / \mathrm{h}$. The coronary sinusarterial ${ }^{14} \mathrm{CO}_{2}$ difference is shown vs. time in the same subject (bottom graph). A, arterial; CS, coronary sinus; $\square$, specific activity of arterial glucose; $\Delta$, coronary sinus glucose.
Chemical analysis. Blood samples for lactate, glucose, specific activities, and $\left[{ }^{13} \mathrm{C}\right]$ lactate analysis were mixed immediately with a measured volume of cold $7 \%$ perchloric acid and centrifuged; the protein-free supernatant was removed and stored at $-4^{\circ} \mathrm{C}$ for future analyses.

The lactate concentration was determined on the protein-free fluid by an enzymatic spectrophotometric method (30). For this method, the coefficient of variation of 50 analyses of one blood sample in our laboratory was $1.6 \%$. Glucose was measured on the protein-free fluid by a hexokinase/glucose-6-phosphate dehydrogenase-coupled enzymatic method, with a coefficient of variation of $1.5 \%$ (31).

Blood for free fatty acids was placed in iced, heparinized glass tubes within $30 \mathrm{~s}$ of sampling, centrifuged at $4^{\circ} \mathrm{C}$, and then separated. Free fatty acid levels were determined immediately on the plasma by the modification by Trout et al. (32) of the Dole procedure (33). The coefficient of variation for this determination was $3.5 \%$.

Glucose, lactate, and pyruvate were separated by ion exchange chromatography as previously described (29). The protein-free fluid was neutralized and passed successively through cation and anion exchange columns to remove labeled ionic compounds. Portions of the eluates containing glucose in $\mathrm{H}_{2} \mathrm{O}$ and lactate in $0.25 \mathrm{M}$ sodium acetate were assayed by the described enzymatic methods. Other portions were mixed with Aquasol (New England Nuclear, Boston, MA) and ${ }^{14} \mathrm{C}$ was measured in a scintillation counter. The results of scintillation counting are expressed as disintegrations per minute (dpm) and the specific activity is calculated as dpm per micromol. The coefficient of variation for specific activity of lactate was $2.5 \%$ in our laboratory (six analyses of one sample).

The ${ }^{14} \mathrm{CO}_{2}$ was collected directly from blood by a diffusion method as previously published (29). The coefficient of variation for this method was $2.9 \%$.

$\left[\mathrm{U}-{ }^{13} \mathrm{C}\right]$ Lactate content was determined using gas chromatography/ mass spectrometry (27). The protein-free fluid was neutralized with potassium carbonate and passed successively through a cation exchange column, $\mathrm{H}^{+}$form (AG50W-X8; Bio-Rad Laboratories, Richmond, CA), and an anion exchange column, $\mathrm{Cl}^{-}$form (AGl-X8; Bio-Rad Laboratories). The effluent was lyophilized and the lactic acid was converted to the methyl ester using $\mathrm{BCl}_{3} /$ methanol. The excess $\mathrm{BCl}_{3} /$ methanol was carefully evaporated to dryness with a stream of $\mathrm{N}_{2}$ to avoid loss of the methyl ester. The dry residue was then extracted with a small quantity of methylene chloride. With the addition of bis(trimethylsilyl)-trifluoroacetamide (BSTFA) (Supelco, Inc., Bellefonte, PA), the methyl ester was converted to the trimethylsilyl ether. The concentration of triply labeled trimethylsilyl ether of $\left[{ }^{13} \mathrm{C}\right]$ methyl lactate was determined using a gas chromatograph (model 2400; Infratonics, Dohrmann Envirotech, Mountain View, CA) interfaced to a mass spectrometer (MS-12; Kratos Analytical Instruments, Ramsey, NJ). The gas chromatograph used a 4-m $\times 2$-mm glass U-tube column packed with $10 \%$ SP-2250 on $100 /$ 120 Supelcoport (Supelco, Inc.) at $125^{\circ} \mathrm{C}$ isothermal and a helium flow rate of $25 \mathrm{ml} / \mathrm{min}$. The mass spectrometric operating conditions were as follows: ion source temperature, $180^{\circ} \mathrm{C}$; nominal base accelerating voltage, $8 \mathrm{kV}$; trap current, $500 \mu \mathrm{A}$; electron energy, $50 \mathrm{eV}$; resolving power, 1,200 . For the determination of percent of $\left[\mathrm{U}-{ }^{13} \mathrm{C}\right]$ lactate, the ion currents were recorded at $\mathrm{m} / \mathrm{e} 161$ and at $\mathrm{m} / \mathrm{e} 164$.

Standards containing $0.0,0.5,0.75,1.0,1.5$, and $2.0 \%\left[\mathrm{U}-{ }^{13} \mathrm{C}\right]$ lactic acid were prepared by dilution with unlabeled lactic acid. The standards were treated in the same fashion as column effluents described above. A standard curve was obtained on the gas chromatograph/mass spectrometer for each set of assays. 12 analyses of a pooled blood sample containing $1.44 \%\left[\mathrm{U}-{ }^{13} \mathrm{C}\right]$ lactate gave a coefficient of variation of $3.7 \%$ for this method.

All isotopic and chemical analyses were performed in duplicate.

Calculations. Glucose was labeled in the C-6 position. This carbon is released as ${ }^{14} \mathrm{CO}_{2}$ in the citric acid cycle (34). By measuring the coronary sinus (CS)-arterial (A) ${ }^{14} \mathrm{CO}_{2}$ difference, the amount of glucose being oxidized (in micromoles per milliliter) was calculated as

$$
(\mathrm{CS}-\mathrm{A})^{14} \mathrm{CO}_{2} \mathrm{dpm} / \mathrm{ml}
$$

arterial specific activity of glucose

The chemical extraction ratio (percent) for a given substrate was 
calculated from the arterial and coronary sinus substrate chemical concentration as

$\frac{[\mathrm{A}]-[\mathrm{CS}]}{[\mathrm{A}]} \times 100$,

where $[\mathrm{A}]$ is the arterial concentration and $[\mathrm{CS}]$ is the coronary sinus concentration.

The isotope or $\left[\mathrm{U} \cdot{ }^{13} \mathrm{C}\right]$ lactate extraction ratio (percent) was calculated from the concentration of $\left[\mathrm{U}-{ }^{13} \mathrm{C}\right]$ lactate in the artery and coronary sinus as $\frac{[\mathrm{A}] \times \%{ }^{13} \mathrm{C}_{3} \text { in artery }-[\mathrm{CS}] \times \%{ }^{13} \mathrm{C}_{3} \text { in coronary sinus }}{[\mathrm{A}] \times \%{ }^{13} \mathrm{C}_{3} \text { in artery }} \times 100$,

where

$\%{ }^{13} \mathrm{C}_{3}=\frac{\left[{ }^{13} \mathrm{C}_{3}\right] \text { lactate }}{\text { chemical lactate }} \times 100$

(percent ${ }^{13} \mathrm{C}_{3}$ is obtained directly from gas chromatography/mass spectrometry).

Myocardial lactate uptake (micromoles per milliliter) was determined by the isotope technique as

$[\mathrm{A}] \times \frac{\left[\mathrm{U}-{ }^{13} \mathrm{C}\right] \text { lactate extraction ratio }}{100}$.

The amount of lactate (micromoles per milliliter) released or produced by the myocardium was calculated as

$\left[\mathrm{U}-{ }^{13} \mathrm{C}\right]$ lactate uptake - ([A] - [CS]).

The contribution of exogenous glucose to the lactate released or produced was calculated from the observed and theoretical disintegrations per minute (dpm) of lactate per milliliter of blood in the coronary sinus and the specific activity of arterial glucose as

$\underline{\text { (observed }- \text { theoretical) } \mathrm{dpm} \text { lactate } / \mathrm{ml} \text { in coronary sinus }} \times 2$. specific activity of arterial glucose

Note the factor of 2 was used because one molecule of glucose yields two molecules of lactate.

The actual or observed dpm of lactate per milliliter of blood in the coronary sinus was calculated as

$[C S] \times$ specific activity of coronary sinus lactate.

The theoretical dpm due to lactate per milliliter of blood was determined as

([A] - $\left[\mathrm{U}-{ }^{13} \mathrm{C}\right]$ lactate uptake in $\left.\mu \mathrm{mol} / \mathrm{ml}\right)$

$X$ specific activity of arterial lactate.

Statistical analysis. Simple and multiple linear regression analyses were performed for the various metabolic parameters and the standard errors of the estimate were calculated. The data are presented as mean \pm 1 SD. To compare the arterial substrate levels and myocardial substrate extraction and oxidation at each of the two or three sampling points in the subjects, two-way analysis of variance and the Newman-Keuls test were used (35). The two-tailed unpaired $t$ test was used to determine whether there was a difference in glucose oxidation between the various arterial levels of free fatty acids.

\section{Results}

The study group consisted of 23 healthy male subjects, $24.6 \pm 4.8$ $\mathrm{yr}$ of age (mean $\pm \mathrm{SD})$. The arterial levels of glucose, lactate, and free fatty acids and the respective myocardial chemical extraction ratios are given in Table $I$. After $30 \mathrm{~min}$ of isotope infusion, the specific activity of arterial glucose in these subjects was $379 \pm 84$ $\mathrm{dpm} / \mu \mathrm{mol}$. When $\left[6-{ }^{14} \mathrm{C}\right]$ glucose is infused, secondary labeling
Table I. Arterial Substrates and Myocardial Chemical Substrate Uptake

\begin{tabular}{llll}
\hline & $\begin{array}{l}\text { Arterial } \\
\text { substrate levels }\end{array}$ & $\begin{array}{l}\text { Arterial-coronary sinus } \\
\text { differences }\end{array}$ & $\begin{array}{l}\text { Chemical } \\
\text { extraction ratios }\end{array}$ \\
\hline & $\mu \mathrm{mol} / \mathrm{ml}$ & $\mu \mathrm{mol} / \mathrm{ml}$ & $\%$ \\
Glucose & $5.22 \pm 0.37$ & $0.23 \pm 0.16$ & $4.2 \pm 3.0$ \\
Lactate & $0.66 \pm 0.17$ & $0.18 \pm 0.14$ & $26.0 \pm 16.4$ \\
Free fatty acids & $0.67 \pm 0.26$ & $0.20 \pm 0.07$ & $32.0 \pm 7.3$
\end{tabular}

Data are presented as mean \pm 1 SD.

of other substrates occurs. The specific activity of arterial lactate at the time of the metabolic sampling was $56 \pm 15 \mathrm{dpm} / \mu \mathrm{mol}$.

Glucose uptake vs. oxidation. In this study, the glucose was labeled with ${ }^{14} \mathrm{C}$ in the sixth position. This carbon is removed in the citric acid cycle (34). Thus, by measuring the myocardial production of ${ }^{14} \mathrm{CO}_{2}$, the amount of glucose undergoing oxidation by the myocardium can be determined. Fig. 2 compares the amount of glucose extracted with the amount of glucose undergoing oxidation in the myocardium. The dashed line represents the line of identity, i.e., data points would fall on this line if $100 \%$ of the glucose extracted were oxidized. In these fasting, resting normal subjects, $20.1 \pm 19.4 \%$ of the glucose extracted undergoes immediate oxidation by the myocardium.

When ${ }^{14} \mathrm{CO}_{2}$ is used to assess glucose oxidation, the contribution of ${ }^{14} \mathrm{C}$ from oxidation of other metabolic substrates labeled secondarily must be taken into account. Since lactate is an important myocardial substrate and we have previously demonstrated that $85-90 \%$ of the lactate extracted undergoes immediate oxidation (29), we corrected the ${ }^{14} \mathrm{CO}_{2}$ data for the possible complete oxidation of lactate in this report. Glucose and lactate were separated from other substrates using ion exchange chromatography. Having determined the arterial specific activity of lactate and the myocardial extraction ratio, we calculated the total amount of ${ }^{14} \mathrm{CO}_{2}$ that could be derived from lactate oxidation. The coronary sinus-arterial ${ }^{14} \mathrm{CO}_{2}$ difference was then corrected for lactate oxidation before myocardial glucose oxidation was calculated. Without this ${ }^{14} \mathrm{CO}_{2}$ correction, the percent of glucose extracted being oxidized would be $30.4 \pm 23.3 \%$ compared with the corrected value of $20.1 \pm 19.4 \%$.

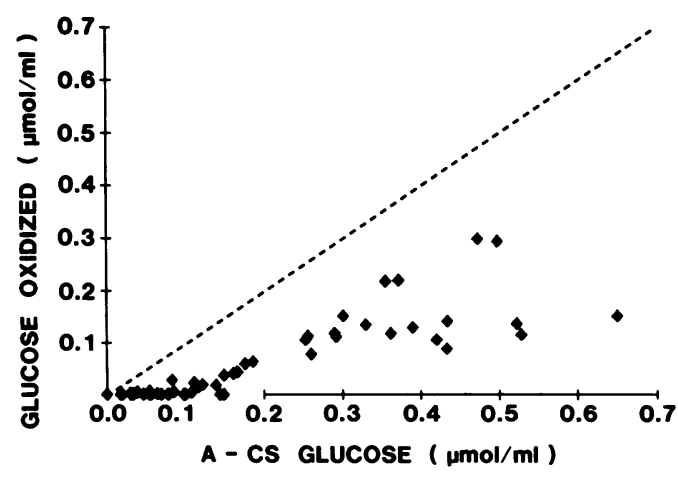

Figure 2. The amount of glucose undergoing immediate oxidation in the myocardium is plotted against the amount of glucose extracted by the myocardium at each sampling point $(n=51)$ in the 23 subjects. The dashed line represents the line of identity, i.e., data points would fall on this line if $100 \%$ of the glucose extracted by the myocardium underwent oxidation. A, arterial; CS, coronary sinus. 


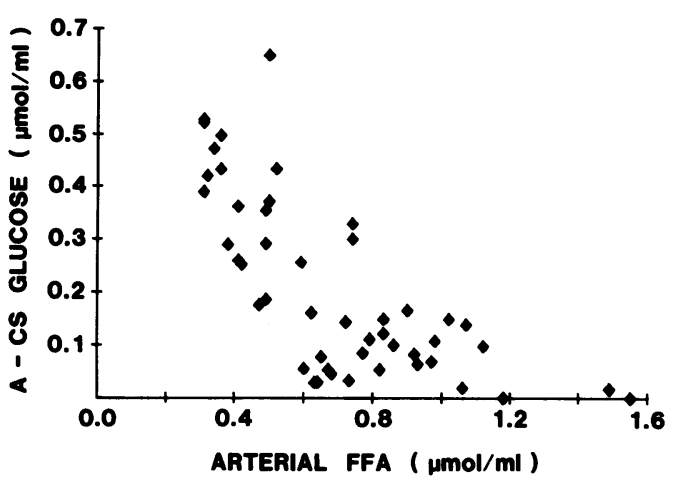

Figure 3. Correlation between the arterial level of free fatty acids (FFA) and myocardial glucose uptake (arterial-coronary sinus difference) of glucose in the 23 normal healthy male subjects. Linear regression analysis gives $r=-0.71(P<0.0001)$ with an $n$ of 49 , $Y=-0.41 X+0.49 ;$ SE of the estimate $Y$ on $X=0.14 \mu \mathrm{mol} / \mathrm{ml}$. A, arterial; CS, coronary sinus; FFA, free fatty acids.

Circulating free fatty acids and glucose uptake. The relationship between the arterial level of free fatty acids and the myocardial uptake of glucose is shown in Fig. 3. The mean arterial level of free fatty acids in these fasting subjects was 0.67 $\mu \mathrm{mol} / \mathrm{ml}$, with a range from 0.31 to $1.55 \mu \mathrm{mol} / \mathrm{ml}$. There is a highly significant inverse correlation between the arterial level of free fatty acids and myocardial glucose uptake $(r=-0.71$; $P<0.0001$ ).

As the circulating levels of free fatty acids increase, the amount of glucose being oxidized by the myocardium decreases. Table II compares myocardial glucose uptake, glucose oxidation, and the percent of glucose extracted being oxidized with various arterial levels of free fatty acids. There is a significant decrease in the portion of glucose extracted that undergoes immediate oxidation when the arterial level of free fatty acid rises above $0.50 \mu \mathrm{mol} / \mathrm{ml}(37.9 \pm 14.4$ vs. $11.8 \pm 15.6 \%$, respectively; $P$ $<0.0001)$. Similarly, as the circulating free fatty acid becomes even greater, i.e., $>1.00 \mu \mathrm{mol} / \mathrm{ml}$, there is a further fall in the percentage of glucose oxidized $(24.9 \pm 19.3$ compared with $1.8 \pm 4.9 \%$, respectively; $P<0.005$ ). This significant change in the percent of extracted glucose being oxidized indicates that

Table II. Comparison of Myocardial Glucose Uptake and Oxidation at Various Free Fatty Acid Levels

\begin{tabular}{llll}
\hline $\begin{array}{l}\text { Arterial free } \\
\text { fatty acids }\end{array}$ & $\begin{array}{l}\text { Myocardial } \\
\text { glucose uptake }\end{array}$ & $\begin{array}{l}\text { Myocardial } \\
\text { glucose oxidized }\end{array}$ & $\begin{array}{l}\text { Percent of glucose } \\
\text { extracted being } \\
\text { oxidized }\end{array}$ \\
\hline$\mu \mathrm{mol} / \mathrm{ml}$ & $\mu \mathrm{mol} / \mathrm{ml}$ & $\mu \mathrm{mol} / \mathrm{ml}$ & $\%$ \\
$\leq 0.5$ & $0.38 \pm 0.13$ & $0.14 \pm 0.07$ & $37.9 \pm 14.4^{*}$ \\
$0.51-0.75$ & $0.16 \pm 0.15$ & $0.06 \pm 0.07$ & $18.6 \pm 20.9$ \\
$0.76-0.99$ & $0.10 \pm 0.04$ & $0.01 \pm 0.02$ & $11.8 \pm 11.9$ \\
$\geq 1.00$ & $0.06 \pm 0.07$ & $0.00 \pm 0.01$ & $1.8 \pm 4.9 \ddagger$ \\
\hline
\end{tabular}

* $P<0.0001$ for percent values with free fatty acid levels below or equal to $0.50 \mu \mathrm{mol} / \mathrm{ml}$ compared with percent values when free fatty acid levels are $>0.50 \mu \mathrm{mol} / \mathrm{ml}$.

$\ddagger P<0.005$ for percent values with free fatty acid levels below 1.00 $\mu \mathrm{mol} / \mathrm{ml}$ compared with percent values when free fatty acids are $>1.00 \mu \mathrm{mol} / \mathrm{ml}$. the circulating level of free fatty acids is also inversely correlated with myocardial glucose oxidation.

Arterial glucose and glucose extraction. The subjects fasted for 10-15 $\mathrm{h}$ before the metabolic sampling. The mean arterial glucose level was $5.22 \mu \mathrm{mol} / \mathrm{ml}$, with a range from 4.40 to 6.22 $\mu \mathrm{mol} / \mathrm{ml}$. Over this narrow range of circulating glucose, there was a positive correlation between the arterial level of glucose and the myocardial extraction of this substrate, as shown in Fig. $4(r=0.54 ; P<0.001)$. In the 23 subjects, there was an inverse correlation between the arterial level of free fatty acids and arterial glucose, with $r=-0.46(P<0.05) ; Y=-0.66 X+5.66$; SE of the estimate $Y$ on $X=0.34 \mu \mathrm{mol} / \mathrm{ml}$.

Multiple linear regression analysis. Multiple linear regression analysis was performed to evaluate the influence of arterial free fatty acids and arterial glucose as important variables in myocardial glucose uptake. In the 23 subjects, the $t$ value was 4.967 for the free fatty acids $(P<0.0001)$ and 1.627 for glucose $(P=0.11)$. Thus, in the fasting, resting state, the circulating level of free fatty acids is more important than the glucose level in determining myocardial glucose extraction.

Circulating exogenous glucose to lactate. When $\left[{ }^{14} \mathrm{C}\right]$ glucose is infused, lactate is labeled secondarily. In all subjects receiving $\left[{ }^{14} \mathrm{C}\right]$ glucose, the specific activity of the coronary sinus lactate was different from that in the artery. This finding indicates that lactate is being released by the myocardium.

To quantitate the amount of lactate released and the contribution of circulating exogenous glucose to lactate, dual-carbon-labeled isotope studies using $\mathrm{D}-\left[6-{ }^{14} \mathrm{C}\right]$ glucose and L-[U$\left.{ }^{13} \mathrm{C}\right]$ lactate were performed in 13 of the 23 subjects. Traditional chemical lactate analysis showed net extraction in all 13 subjects with an arterial-coronary sinus difference of $0.18 \pm 0.13 \mu \mathrm{mol} /$ $\mathrm{ml}$ and a myocardial chemical extraction ratio of $26.8 \pm 14.9 \%$. The isotope extraction ratio determined by the $\left[\mathrm{U}-{ }^{13} \mathrm{C}\right]$ lactate was significantly greater, $41.4 \pm 17.7 \%(P<0.0001$; isotope extraction ratios vs. chemical ratios). The isotope extraction ratio was greater than the chemical ratio because unlabeled lactate was being released by the myocardium, thereby elevating the chemical concentration in the venous effluent of the heart (coronary sinus). The calculated amount of lactate released by the myocardium in these 13 subjects was $0.09 \pm 0.04 \mu \mathrm{mol} / \mathrm{ml}$. Measuring the specific activity of arterial glucose and the dpm of the secondarily labeled lactate in the artery and coronary sinus, the

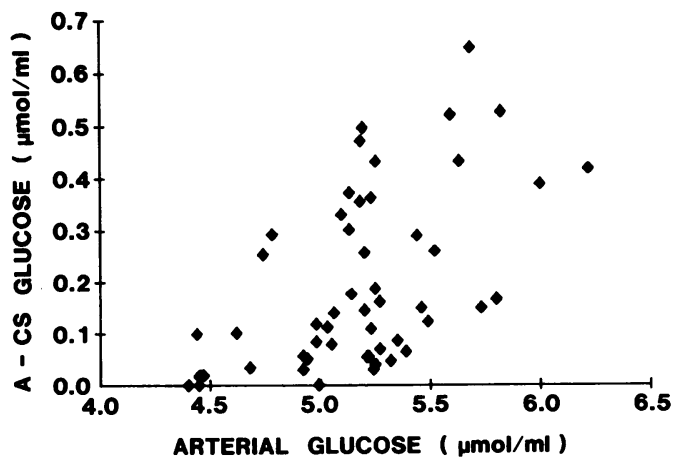

Figure 4. The myocardial glucose extraction (arterial-coronary sinus difference) is plotted against the arterial level of glucose in all data points in the 23 fasting subjects. Linear regression analysis gives $r=0.54(P<0.001)$ with an $n$ of 52, $Y=0.23 X-1.00$; SE of the estimate $Y$ on $X=0.14 \mu \mathrm{mol} / \mathrm{ml}$. A, arterial; CS, coronary sinus. 
amount of exogenous glucose being converted to lactate and released can be calculated. The myocardial glucose uptake, glucose oxidation, and the amount of exogenous glucose converted to lactate in the 13 subjects receiving dual-carbon-labeled isotopes are given in Table III. Of the $0.21 \pm 0.15 \mu \mathrm{mol} / \mathrm{ml}$ exogenous glucose extracted by the myocardium, $27.9 \pm 21.8 \%$ undergoes oxidation immediately, while $13.0 \pm 9.0 \%$ is converted to lactate and released.

There was no significant correlation between the arterialcoronary sinus difference of glucose and the amount of lactate released in these 13 subjects $(r=0.38 ; P<0.20)$. However, there was a positive correlation between the glucose extracted and the amount of glucose proceeding through glycolysis and being released as lactate $(r=0.62 ; P<0.025)$ (Table III).

Arterial levels of free fatty acids and lactate uptake. We have previously shown using $\mathrm{L}-\left[1-{ }^{14} \mathrm{C}\right]$ lactate in humans that the amount of lactate undergoing oxidative decarboxylation is closely correlated with the isotopic lactate uptake (29) and that the myocardial lactate uptake determined by the $\left[1-{ }^{14} \mathrm{C}\right]$ lactate tracer is identical to the $\left[\mathrm{U}_{-}{ }^{13} \mathrm{C}\right]$ lactate uptake (27). In the 13 subjects receiving dual-carbon-labeled isotopes, an inverse correlation was found between the circulating level of free fatty acids and the myocardial lactate uptake determined by the stable isotope ( $r=-0.73 ; P<0.005$ ). Thus, it appears that the circulating level of free fatty acids not only has an effect on myocardial glucose extraction and oxidation, but also has a significant negative effect on myocardial lactate uptake. There was no correlation between the amount of lactate released by the myocardium and the arterial free fatty acid level $(r=-0.15 ; P>0.5)$.

\section{Discussion}

Interest in myocardial substrate utilization began in 1907 when Locke and Rosenheim (36) first reported glucose uptake in the Langendorff heart preparation. In 1914, Evans (37) suggested that carbohydrates supplied one-third of the energy for the myocardium. Since these early studies, many investigators have measured glucose uptake in isolated heart and anesthetized an- imal preparations. With the advent of the coronary sinus catheter in 1947 , Bing et al. $(38,39)$ began to study myocardial substrate extraction in humans. Substrate utilization was assessed by measuring the arterial-coronary sinus difference. If a substrate was extracted, it was often assumed that $100 \%$ was oxidized to meet the energy requirements of the myocardium during a particular physiologic state or after a pharmacologic intervention $(12,22)$. In 1961, Shipp and colleagues (40) were the first to use radioisotopes to investigate the metabolic fate of various substrates in isolated heart preparations.

Using D- $\left[6-{ }^{14} \mathrm{C}\right]$ glucose, we measured myocardial glucose uptake and glucose oxidation, and in a subset of subjects, the conversion of glucose to lactate was also determined by using a dual-carbon-labeled isotope technique. This is the first study to quantitate myocardial glucose oxidation in human subjects. By using carbon-labeled glucose in the sixth position and measuring the myocardial production of ${ }^{14} \mathrm{CO}_{2}$, we found that only $20 \%$ (range, 0-63\%) of the glucose extracted by the myocardium underwent immediate oxidation in the citric acid cycle in these fasting, resting subjects. Thus, the uptake of exogenous glucose by the human myocardium cannot be equated with oxidation.

Isolated heart experiments (40-45) have shown that the addition of free fatty acids to the perfusion media inhibits myocardial glucose utilization. Several of these studies can be criticized for using low glucose concentrations and high, nonphysiologic free fatty acid/albumin ratios. However, our findings support the concept that free fatty acids play a major role in myocardial glucose uptake. There is a highly significant inverse correlation between the arterial level of free fatty acids and myocardial glucose uptake determined by the arterial-coronary sinus difference (Fig. 3). Lassers and colleagues $(46,47)$ lowered the arterial level of free fatty acids with nicotinic acid in healthy subjects and demonstrated a negative correlation between arterial free fatty acids and myocardial glucose extraction. Since Lassers and colleagues did not use a glucose isotope, they were not able to assess glucose oxidation.

In this study, an inverse correlation was found between the arterial level of free fatty acids and arterial glucose $(r=-0.46$;

Table III. Comparison of Myocardial Glucose Uptake, Glucose Oxidation, and Glucose Being Converted to Lactate in Subjects Receiving Dual-Carbon-Labeled Isotopes

\begin{tabular}{|c|c|c|c|c|c|}
\hline Subject & $\begin{array}{l}\text { Glucose uptake } \\
\text { (A-CS) }\end{array}$ & Glucose oxidized & $\begin{array}{l}\text { Glucose converted } \\
\text { to lactate }\end{array}$ & $\begin{array}{l}\text { Total lactate } \\
\text { released }\end{array}$ & $\begin{array}{l}\text { Arterial } \\
\text { free fatty acids }\end{array}$ \\
\hline & $\mu \mathrm{mol} / \mathrm{ml}$ & $\mu \mathrm{mol} / \mathrm{ml}$ & $\mu \mathrm{mol} / \mathrm{ml}$ & $\mu \mathrm{mol} / \mathrm{ml}$ & $\mu \mathrm{mol} / \mathrm{ml}$ \\
\hline 1 & 0.07 & 0.00 & 0.00 & 0.03 & 0.80 \\
\hline 2 & 0.11 & 0.02 & 0.04 & 0.15 & 0.79 \\
\hline 3 & 0.04 & 0.00 & 0.01 & 0.06 & 0.65 \\
\hline 4 & 0.36 & 0.22 & 0.04 & 0.13 & 0.50 \\
\hline 5 & 0.05 & 0.00 & 0.00 & 0.06 & 0.97 \\
\hline 6 & 0.17 & 0.04 & 0.02 & 0.09 & 0.86 \\
\hline 7 & 0.32 & 0.14 & 0.06 & 0.12 & 0.74 \\
\hline 8 & 0.26 & 0.11 & 0.04 & 0.13 & 0.59 \\
\hline 9 & 0.04 & 0.00 & 0.00 & 0.04 & 0.62 \\
\hline 10 & 0.48 & 0.30 & 0.02 & 0.06 & 0.35 \\
\hline 11 & 0.18 & 0.06 & 0.03 & 0.10 & 0.48 \\
\hline 12 & 0.27 & 0.11 & 0.04 & 0.12 & 0.46 \\
\hline 13 & 0.40 & 0.10 & 0.03 & 0.09 & 0.38 \\
\hline Mean \pm SD & $0.21 \pm 0.15$ & $0.08 \pm 0.09$ & $0.03 \pm 0.02$ & $0.09 \pm 0.04$ & $0.63 \pm 0.19$ \\
\hline
\end{tabular}


$P<0.05)$. If the data points following heparin administration are eliminated, there was still a wide range of circulating free fatty acids $(0.31-1.12 \mu \mathrm{mol} / \mathrm{ml})$ and arterial glucose (4.44-6.22 $\mu \mathrm{mol} / \mathrm{ml}$ ) in these subjects. Although all subjects fasted 10-15 $h$, there was no attempt to control their diets before the study. Dietary habits probably have an effect on the variability of the fasting substrate levels. The interrelationship of circulating metabolic substrates in vivo is very complex, and it is well recognized that a number of factors such as insulin, growth hormone, glucocorticoid levels, and the adrenergic state of the individual have a very important role in determining the arterial substrate levels $(44,48)$. These factors were not measured in the present study. Wahlqvist and colleagues (49) have investigated the effects of these hormones on the myocardial glucose chemical extraction ratio. In their study, multiple regression analysis showed that there was a significant positive relationship between the insulin level and myocardial glucose extraction. The glucocorticoid levels had a significant inverse correlation with myocardial uptake of glucose and there was no correlation between growth hormone levels and the myocardial extraction of this substrate. Their study also showed a highly significant inverse relationship between myocardial free fatty acid extraction and glucose uptake.

In addition to the inverse correlation between free fatty acids and glucose uptake or transport into the cell, we also demonstrated in this study a negative correlation between the arterial level of free fatty acids and myocardial glucose oxidation. Although the average value for oxidation was $20 \%$ of glucose extracted, there was a wide range of values from 0 to $63 \%$. When the level of free fatty acids was low $(\leq 0.5 \mu \mathrm{mol} / \mathrm{ml})$, not only was the myocardial glucose uptake higher, but the portion or percent of the extracted glucose undergoing immediate oxidation was also significantly higher compared with the percent oxidized when the free fatty acid values were $>0.5 \mu \mathrm{mol} / \mathrm{ml}(P<0.0001)$. Similarly, if the arterial free fatty acid level was $\geq 1.00 \mu \mathrm{mol} /$ $\mathrm{ml}$, the percent of extracted glucose being oxidized was significantly lower $(P<0.005)$ (Table II). Therefore, our results demonstrate that the circulating level of free fatty acids plays a major role not only in determining myocardial glucose extraction but also glucose oxidation.

In very elegant isolated heart experiments, Randle and associates $(44,50-52)$ have shown that free fatty acids affect glucose uptake and oxidation at several enzymatic steps in the glycolytic pathway. The supply of ATP in the cell regulates the various metabolic pathways. If the cell is utilizing free fatty acids, the ATP level is high and the level of acetyl-coenzyme A increases. With high levels of acetyl-coenzyme $A$, the enzyme pyruvate dehydrogenase is inhibited. This enzyme is involved in the oxidative decarboxylation of pyruvate; thus, inhibition of pyruvate dehydrogenase blocks the entry of glucose into the citric acid cycle. Also, when the myocardium is actively utilizing free fatty acids, there is a build-up of citrate. Citrate inhibits the enzyme phosphofructokinase in the glycolytic pathway. When this latter enzyme is inhibited, glucose-6-phosphate accumulates in the cell. As this occurs, the enzyme hexokinase is inhibited, thus blocking further phosphorylation of glucose. Increased levels of free fatty acids also block glucose transport into the cell.

These experiments by Randle and associates (50-52) were performed in an isolated rat heart preparation with a low ventricular workload. Opie and colleagues (53) have shown that glucose utilization increases in the isolated rat heart when the workload is increased. In our study, myocardial glucose uptake and glucose oxidation were measured in vivo in human subjects and our findings support the suggestion that elevating free fatty acids has an inhibitory effect on myocardial glucose uptake (glucose transport) and glucose oxidation in the fasting, resting state. No intervention was performed in this study to increase myocardial work.

There are several metabolic pathways for glucose following extraction by the myocardium: oxidation through the citric acid cycle, storage as glycogen, utilization by the hexose monophosphate shunt pathway, and conversion to lactate through the glycolytic pathway $(45,54)$. Using $\left[6-{ }^{14} \mathrm{C}\right]$ glucose and measuring the myocardial production of ${ }^{14} \mathrm{CO}_{2}$ enabled us to quantitate the amount of exogenous glucose that underwent immediate oxidation since the carbon in the sixth position is released during oxidation in the citric acid cycle. The dual-carbon-labeled isotope experiments with $\left[6-{ }^{14} \mathrm{C}\right]$ glucose and $\left[\mathrm{U}-{ }^{13} \mathrm{C}\right]$ lactate allowed quantitation of the amount of lactate being released or produced by the myocardium and the contribution of exogenous glucose to the lactate released. In the subjects receiving dual-carbonlabeled isotopes, $27.9 \pm 21.8 \%$ of the extracted glucose underwent immediate oxidation, while $13.0 \pm 9.0 \%$ was converted to lactate and released by the myocardium. Thus, $60 \%$ of the extracted glucose was not accounted for and was probably stored as glycogen. In the adult, noninfarcted myocardium, very little (10\%) of the extracted glucose is thought to be utilized by the pentose shunt (54-56). However, since the carbon in the first position is released as $\mathrm{CO}_{2}$ in the pentose pathway, the amount of glucose being shunted through this pathway could not be assessed in our experiments with $\left[6-{ }^{14} \mathrm{C}\right]$ glucose.

In 1907, Fletcher and Hopkins (57) demonstrated that hypoxia of skeletal muscle was associated with lactate production and that with improved oxygenation there was a decrease in the amount of lactate produced. Other investigators (36) found a similar relationship in isolated heart preparations; under conditions of normoxia and adequate perfusion, there was no lactate production in these preparations. Thus, myocardial lactate release or production is often equated with hypoxia or ischemia. However, since these early experiments, several investigators (6, $8,40-42,45,53,58)$ have quantitated lactate production in isolated heart and myocardial cell preparations and the importance of the glycolytic pathway under normoxic conditions has been raised. The high energy phosphates derived from glycolysis may be preferentially used for the sarcoplasmic reticulum and promote myocardial relaxation (59-61). Another function of the glycolytic pathway might be to provide a rapid source of energy for sudden increases in cardiac work $(53,62)$.

In addition to being an end-product of the glycolytic pathway, lactate is also an important metabolic substrate for the myocardium. Thus, there can be simultaneous uptake and release of lactate by the heart muscle. In the isolated heart and myocardial cell preparations, lactate is usually not present as a substrate in the perfusion media; therefore, the measurement of myocardial lactate production is simplified. Few in vivo studies $(4,63)$ have attempted to quantitate simultaneous myocardial lactate production and lactate extraction. Using a tracer method, we reported previously (29) that there is a simultaneous uptake and release of lactate by the myocardium in patients with significant coronary artery stenoses. Using a similar technique, Leunissen and Piatnek-Leunissen (64) demonstrated simultaneous myocardial lactate release and uptake in anesthetized open-chest dog preparations. In this study, we have quantitated myocardial lactate release in vivo in young, healthy human subjects.

Myocardial biopsy studies in animals have shown differences 
in enzymes and substrate storage in the epicardial and endocardial regions (65-67). The subendocardium contains more glycogen, has increased levels of certain glycolytic enzymes, and has increased phosphorylase activity. These findings suggest that the glycolytic pathway with the use of carbohydrates as a myocardial energy source may be greater in the subendocardial layers. In the in vivo working human heart during peak systolic pressure, there may be hypoperfusion of the subendocardial layers, which results in this transmural gradient in myocardial substrate utilization. The source of the myocardial lactate release that we demonstrated in our study might be the subendocardial region.

The autoregulatory mechanisms that control myocardial blood flow have been investigated in animal experiments (68, 69). Autoregulation is considered to be mediated by several metabolic and neurogenic factors; the contribution of each of these factors in the normal human myocardium is uncertain (70). Recently, several investigators $(71,72)$ have demonstrated that alpha-adrenergic tone has a significant effect in the normal human myocardium and that alpha-adrenergic blockade significantly increases blood flow. Blood flow is maintained through autoregulation to achieve a certain level of oxygenation in the tissue bed; however, the flow to various regions or areas of the myocardium may be changing continuously. Thus, areas of the intact myocardium may be underperfused very transiently. Using microspheres in anesthetized open-chest dog preparations, Falsetti and his colleagues (73) demonstrated a $31 \%$ change in flow over time. Small areas of the transiently underperfused myocardium may account for the lactate release observed in this study.

In summary, we have demonstrated that the circulating level of free fatty acids is a major determinant of both myocardial glucose uptake and oxidation in humans. At high levels of free fatty acids $(\sim 1.0 \mu \mathrm{mol} / \mathrm{ml})$, there is inhibition of glucose extraction and oxidation. In the fasting, resting state, only a small fraction $(20 \%)$ of the glucose extracted undergoes oxidation. Even at low free fatty acids, i.e., $<0.5 \mu \mathrm{mol} / \mathrm{ml}$, only $40 \%$ of the glucose extraction underwent immediate oxidation. We have found that in the normal human myocardium, there is myocardial lactate release despite global net extraction. $10-20 \%$ of the glucose extracted was converted to lactate and released in the venous effluent in these normal subjects. The remainder (60-70\%) of the glucose extracted is probably stored as glycogen. The importance of glucose as a myocardial substrate and its metabolic fate needs to be assessed further in humans under various physiologic and pathologic conditions.

\section{Acknowledgments}

We express our appreciation to Maria Mayr and Chit S. Kwan for their assistance with the biochemical assays, to Mary Parks for her technical assistance in the catheterization laboratory, and to Pat Paulson for her secretarial assistance.

This work was supported in part by the Medical Research Service of the Veterans Administration, San Francisco, CA, and by grant HL-25625 from the National Institutes of Health, California Heart Association grant 84-N108, and a Merck Fellowship of the American College of Cardiology. $\mathrm{L}-\left[\mathrm{U}-{ }^{13} \mathrm{C}\right]$ Lactic acid was obtained from the Los Alamos Stable Isotope Resource, Los Alamos, NM, and this resource is supported by National Institutes of Health grant P41RR00962.

\section{References}

1. Opie, L. H. 1968. Metabolism of the heart in health and disease. Part 1. Am. Heart J. 76:685-698.
2. Neely, J. R., M. J. Rovetto, and J. F. Oram. 1972. Myocardial utilization of carbohydrate and lipids. Prog. Cardiovasc. Dis. 15:289329.

3. Opie, L. H. 1972. Metabolic response during impending myocardial infarction. I. Relevance of studies of glucose and fatty acids metabolism in animals. Circulation. 45:483-490.

4. Opie, L. H., P. Owen, and R. A. Riemersma. 1973. Relative rates of oxidation of glucose and free fatty acids by ischaemic and non-ischaemic myocardium after coronary artery ligation in the dog. Eur. J. Clin. Invest. 3:419-435.

5. Williamson, J. R. 1966. Glycolytic control mechanisms. II. Kinetics of intermediate changes during the aerobic-anoxic transition in perfused rat heart. J. Biol. Chem. 241:5026-5036.

6. Kobayashi, K., and J. R. Neely. 1979. Control of maximum rates of glycolysis in rat cardiac muscle. Circ. Res. 44:166-175.

7. Opie, L. H. 1976. Effects of regional ischemia on metabolism of glucose and fatty acids. Relative rates of aerobic and anaerobic energy production during myocardial infarction and comparison with effects of anoxia. Circ. Res. 38(Suppl. 1):I52-I74.

8. Rovetto, M. J., J. T. Whitmer, and J. R. Neely. 1973. Comparison of the effects of anoxia and whole heart ischemia on carbohydrate utilization in isolated working rat hearts. Circ. Res. 32:699-711.

9. Opie, L. H. 1970. The glucose hypothesis: relation to acute myocardial ischaemia. J. Mol. Cell. Cardiol. 1:107-115.

10. Rackley, C. E., R. O. Russell, Jr., W. J. Rogers, J. A. Mantle, H. G. McDaniel, and S. E. Papapietro. 1981. Clinical experience with glucose-insulin-potassium therapy in acute myocardial infarction. $\mathrm{Am}$. Heart J. 102:1038-1049.

11. Whitlow, P. L., W. J. Rogers, L. R. Smith, H. G. McDaniel, S. E. Papapietro, J. A. Mantle, J. R. Logic, R. O. Russell, Jr., and C. E. Rackley. 1982. Enhancement of left ventricular function by glucoseinsulin-potassium infusion in acute myocardial infarction. Am. J. Cardiol. 49:811-820.

12. Rogers, W. J., R. O. Russell, Jr., H. G. McDaniel, and C. E. Rackley. 1977. Acute effects of glucose-insulin-potassium infusion on myocardial substrates, coronary blood flow and oxygen consumption in man. Am. J. Cardiol. 40:421-428.

13. Apstein, C. S., F. N. Gravino, and C. C. Haudenschild. 1983. Determinants of a protective effect of glucose and insulin on the ischemic myocardium: effects on contractile function, diastolic compliance, metabolism, and ultrastructure during ischemia and reperfusion. Circ. Res. 52:515-526.

14. Maroko, P. R., P. Libby, B. E. Sobel, C. M. Bloor, H. D. Sybers, W. E. Shell, J. W. Covell, and E. Braunwald. 1972. Effect of glucoseinsulin-potassium infusion on myocardial infarction following experimental coronary artery occlusion. Circulation. 45:1160-1175.

15. Chiong, M. A., R. West, and J. O. Parker. 1976. The protective effect of glucose-insulin-potassium on the response to atrial pacing. Circulation. 54:37-46.

16. Lesch, M., L. E. Teichholz, J. S. Soeldner, and R. Gorlin. 1974. Ineffectiveness of glucose, potassium, and insulin infusion during pacing stress in chronic ischemic heart disease. Circulation. 49:1028-1037.

17. Oliver, M. F. 1972. Metabolic response during impending myocardial infarction. II. Clinical implications. Circulation. 45:491-500.

18. Marshall, R. C., S. C. Huang, W. W. Nash, and M. E. Phelps. 1983. Assessment of the ${ }^{18} \mathrm{~F}$ fluorodeoxyglucose kinetic model in calculations of myocardial glucose metabolism during ischemia. J. Nucl. Med. 24:1060-1064.

19. Schelbert, H. R., E. Henze, M. E. Phelps, and D. E. Kuhl. 1982. Assessment of regional myocardial ischemia by positron-emission computed tomography. Am. Heart J. 103:588-597.

20. Marshall, R. C., J. H. Tillisch, M. E. Phelps, S. C. Huang, R. Carson, E. Henze, and H. R. Schelbert. 1983. Identification and differentiation of resting myocardial ischemia and infarction in man with positron computer tomography, ${ }^{18} \mathrm{~F}$-labeled fluorodeoxyglucose and $\mathrm{N}$ 13 ammonia. Circulation. 67:766-778.

21. Phelps, M. E., E. J. Hoffman, C. Selin, S. C. Huang, G. Robinson, 
N. MacDonald, H. Schelbert, and D. E. Kuhl. 1978. Investigation of ${ }^{18} \mathrm{~F}$ 2-fluoro-2-deoxyglucose for the measure of myocardial glucose metabolism. J. Nucl. Med. 19:1311-1319.

22. Kaijser, L., L. A. Carlson, B. Eklund, E. R. Nye, S. Rossner, and M. L. Wahlqvist. 1972. Substrate uptake by the ischaemic human heart during angina induced by atrial pacing. In Effect of Acute Ischaemia on Myocardial Function. M. F. Oliver, D. G. Julian, and K. W. Donald, editors. The Williams \& Wilkins Co., Baltimore, MD. 223-236.

23. Bruce, R. A., and T. R. Hornsten. 1969. Exercise stress testing in evaluation of patients with ischemic heart disease. Prog. Cardiovasc. Dis. 11:371-390.

24. Sheffield, L. T., and D. Roitman. 1976. Stress testing methodology. Prog. Cardiovasc. Dis. 19:33-49.

25. Mathey, D. G., K. Chatterjee, J. V. Tyberg, J. Lekven, B. Brundage, and W. W. Parmley. 1978. Coronary sinus reflux: a source of error in the measurement of thermodilution coronary sinus flow. Circulation. 57:778-786.

26. Wisneski, J. A., E. W. Gertz, R. Neese, W. J. Soo, J. D. Bristow, J. R. Adams, and J. P. Beaudry. 1982. Myocardial metabolic alterations after contrast angiography. Am. J. Cardiol. 50:239-245.

27. Neese, R. A., E. W. Gertz, J. A. Wisneski, L. D. Gruenke, and J. C. Craig. 1983. A stable isotope technique for investigating lactate metabolism in humans. Biomed. Mass Spectrom. 10:458-462.

28. Reinhold, R. B., and J. Fine. 1971. A technique for quantitative measurement of endotoxin in human plasma. Proc. Soc. Exp. Biol. Med. 137:334-340.

29. Gertz, E. W., J. A. Wisneski, R. Neese, J. D. Bristow, G. L. Searle, and J. T. Hanlon. 1981. Myocardial lactate metabolism: evidence of lactate release during net chemical extraction in man. Circulation. 63:1273-1279.

30. Fleischer, W. R. 1970. Enzymatic methods for lactic and pyruvic acids. In Standard Methods in Clinical Chemistry. R. P. MacDonald, editor. Academic Press, Inc., New York. 6:245-259.

31. Barthelmai, W., and R. Czok. 1962. Enzymatische bestimmungen der glucose in blut, liquor and harn. Klin. Wochenschr. 40:585-589.

32. Trout, D. L., E. H. Estes, Jr., and S. J. Friedberg. 1960. Titration of free fatty acids of plasma: a study of current methods and a new modification. J. Lipid Res. 1:199-202.

33. Dole, V. P. 1956. A relation between non-esterified fatty acids in plasma and the metabolism of glucose. J. Clin. Invest. 35:150-154.

34. Lehninger, A. L. 1975. Biochemistry. Worth Publishers, Inc., New York. 417-473.

35. Zar, J. H. 1974. Biostatistical Analysis. Prentice-Hall, Inc., Englewood Cliffs, NJ. 151-155.

36. Locke, F. S., and O. Rosenheim. 1907. Contributions to the physiology of the isolated heart. J. Physiol. (Lond.). 36:205-220.

37. Evans, L. C. 1914. The effect of glucose on the gaseous metabolism of the isolated mammalian heart. J. Physiol. (Lond.). 47:407-418.

38. Bing, R. J., L. D. Vandam, F. Gregoire, J. C. Handelsman, W. T. Goodale, and J. E. Eckenhoff. 1947. Catheterization of the coronary sinus and the middle cardiac vein in man. Proc. Soc. Exp. Biol. 66:239240.

39. Bing, R. J., A. Siegel, A. Vitale, F. Balboni, E. Sparks, M. Taeschler, M. Klapper, and S. Edwards. 1953. Metabolic studies on the human heart in vivo. I. Studies on carbohydrate metabolism of the human heart. Am. J. Med. 15:284-296.

40. Shipp, J. C., L. H. Opie, and D. Challoner. 1961. Fatty acid and glucose metabolism in the perfused heart. Nature (Lond.). 189:10181019.

41. Opie, L. H., J. R. Evans, and J. C. Shipp. 1963. Effect of fasting on glucose and palmitate metabolism of perfused rat heart. Am. J. Physiol. 205:1203-1208.

42. Neely, J. R., K. M. Whitmer, and S. Mochizuki. 1976. Effects of mechanical activity and hormones on myocardial glucose and fatty acid utilization. Circ. Res. 38(Suppl. 1):I22-I30.

43. Bowman, R. H. 1962. The effect of long-chain fatty acids on glucose utilization in the isolated perfused rat heart. Biochem. J. 84:14P. (Abstr.)

44. Randle, P. J., P. B. Garland, C. N. Hales, and E. A. Newsholme. 1963. The glucose fatty-acid cycle: its role in insulin sensitivity and the metabolic disturbances of diabetes mellitus. Lancet. I:785-789.

45. Opie, L. H., J. C. Shipp, J. R. Evans, and B. Leboeuf. 1962. Metabolism of glucose-U-C ${ }^{14}$ in perfused rat heart. Am. J. Physiol. 203: 839-843.

46. Lassers, B. W., M. L. Wahlqvist, L. Kaijser, and L. A. Carlson. 1971. Relationship in man between plasma free fatty acids and myocardial metabolism of carbohydrate substrates. Lancet. II:448-450.

47. Lassers, B. W., L. Kaijser, and L. A. Carlson. 1972. Myocardial lipid and carbohydrate metabolism in healthy, fasting men at rest: studies during continuous infusion of ${ }^{3} \mathrm{H}$-palmitate. Eur. J. Clin. Invest. 2:348358.

48. West, J. B. 1985. Best and Taylor's Physiologic Basis of Medical Practice. The Williams \& Wilkins Co., Baltimore, MD. 11th edition. 792-817.

49. Wahlqvist, M. L., L. Kaijser, B. W. Lassers, H. Low, and L. A. Carlson. 1973. The role of fatty acid and of hormones in the determination of myocardial carbohydrate metabolism in healthy fasting men. Eur. J. Clin. Invest. 3:57-65.

50. Randle, P. J., E. A. Newsholme, and P. B. Garland. 1964. Regulation of glucose uptake by muscle. 8. Effects of fatty acids, ketone bodies and pyruvate, and of alloxan-diabetes and starvation, on the uptake and metabolic fate of glucose in rat heart and diaphragm muscles. Biochem. J. 93:652-665.

51. Garland, P. B., E. A. Newsholme, and P. J. Randle. 1964. Regulation of glucose uptake by muscle. 9. Effects of fatty acids and ketone bodies, and of alloxan-diabetes and starvation, on pyruvate metabolism and on lactate/pyruvate and L-glycerol 3-phosphate/dihydroxyacetone phosphate concentration ratios in rat heart and rat diaphragm muscles. Biochem. J. 93:665-678.

52. Garland, P. B., and P. J. Randle. 1964. Regulation of glucose uptake by muscle. 10. Effects of alloxan-diabetes, starvation, hypophysectomy and adrenalectomy, and of fatty acids, ketone bodies and pyruvate, on the glycerol output and concentrations of free fatty acids, long-chain fatty acyl-coenzyme A, glycerol phosphate and citrate-cycle intermediates in rat heart and diaphragm muscles. Biochem. J. 93:678687.

53. Opie, L. H., K. R. L. Mansford, and P. Owen. 1971. Effects of increased heart work on glycolysis and adenine nucleotides in the perfused heart of normal and diabetic rats. Biochem. J. 124:475-490.

54. Shipp, J. C., H. K. Delcher, and L. E. Crevasse. 1964. Glucose metabolism by the hexose monophosphate pathway in the perfused rat heart. Biochim. Biophys. Acta. 86:399-402.

55. Jolley, R. L., V. H. Cheldelin, and R. W. Newburgh. 1958. Glucose catabolism in fetal and adult heart. J. Biol. Chem. 233:1289-1294.

56. Fanburg, B. L. 1970. Experimental cardiac hypertrophy. N. Engl. J. Med. 282:723-732.

57. Fletcher, W. M., and F. G. Hopkins. 1907. Lactic acid in amphibian muscle. J. Physiol. (Lond.). 35:247-309.

58. Rosenthal, M. D., and J. B. Warshaw. 1973. Interaction of fatty acid and glucose oxidation by cultured heart cells. J. Cell Biol. 58:332339.

59. Entman, M. L., K. Kaniike, M. A. Goldstein, T. E. Nelson, E. P. Bornet, T. W. Futch, and A. Schwartz. 1976. Association of glycogenolysis with cardiac sarcoplasmic reticulum. J. Biol. Chem. 251: 3140-3146.

60. Anderson, G. L., and R. G. Morris. 1978. Role of glycolysis in the relaxation process in mammalian cardiac muscle: comparison of the influence of glucose and 2-deoxyglucose on maintenance of resting tension. Life Sci. 23:23-32.

61. Weiss, J., and B. Hiltbrand. 1985. Functional compartmentation of glycolytic versus oxidative metabolism in isolated rabbit heart. J. Clin. Invest. 75:436-447.

62. Achs, M. J., D. Garfinkel, and L. H. Opie. 1982. Computer sim- 
ulation of metabolism of glucose perfused rat heart in a work-jump. Am. J. Physiol. 243:R389-R399.

63. Griggs, D. M., Jr., S. Nagano, J. G. Lipana, and P. Novack. 1966. Myocardial lactate oxidation in situ and the effect of reduced coronary flow. Am. J. Physiol. 211:335-340.

64. Leunissen, R. L. A., and D. A. Piatnek-Leunissen. 1973. Myocardial lactate oxidation and release in the dog in vivo. Pfluegers Arch. Eur. J. Physiol. 344:261-270.

65. Ichihara, K., and Y. Abiko. 1975. Difference between endocardial and epicardial utilization of glycogen in the ischemic heart. Am. J. Physiol. 229:1585-1589.

66. Jedeikin, L. A. 1964. Regional distribution of glycogen and phosphorylase in the ventricles of the heart. Circ. Res. 14:202-211.

67. Lundsgaard-Hansen, P., C. Meyer, and H. Riedwyl. 1967. Transmural gradients of glycolytic enzyme activities in left ventricular myocardium. I. The normal state. Pfluegers Arch. Eur. J. Physiol. 297:89106.
68. Berne, R. M. 1964. Regulation of coronary blood flow. Physiol. Rev. 44:1-29.

69. Rouleau, J., L. E. Boerboom, A. Surjadhana, and J. I. E. Hoffman. 1979. The role of autoregulation and tissue diastolic pressures in the transmural distribution of left ventricular blood flow in anesthetized dogs. Circ. Res. 45:804-815.

70. Klocke, F. J. 1976. Coronary blood flow in man. Prog. Cardiovasc. Dis. 19:117-166.

71. Mudge, G. H., Jr., S. Goldberg, S. Gunther, T. Mann, and W. Grossman. 1979. Comparison of metabolic and vasoconstrictor stimuli on coronary vascular resistance in man. Circulation. 59:544-550.

72. Orlick, A. E., D. R. Ricci, E. L. Alderman, E. B. Stinson, and D. C. Harrison. 1978. Effects of alpha adrenergic blockade upon coronary hemodynamics. J. Clin. Invest. 62:459-467.

73. Falsetti, H. L., R. J. Carroll, and M. L. Marcus. 1975. Temporal heterogeneity of myocardial blood flow in anesthetized dogs. Circulation. $52: 848-853$. 